DOI: https://doi.org/10.47133/38201

BIBLID: 0251-2483 (2020-2), 9-31

\title{
LA CONSTRUCCIÓN HISTORIOGRÁFICA DEL NORDESTE ARGENTINO EN RELACIÓN CON EL \\ PARAGUAY
}

\author{
THE HISTORIOGRAPHIC CONSTRUCTION OF \\ NORTHEAST ARGENTINE IN RELATION TO PARAGUAY
}

\section{María Silvia Leoni ${ }^{1}$}

Enviado: $27 / 07 / 2020$

Aceptado: 20/11/2020

Resumen: Este trabajo propone trazar un recorrido reflexivo sobre la emergencia y despliegue de la historiografía referida al nordeste argentino, desde fines del siglo XIX a la década de 1970, producida tanto en vinculación con la historia "nacional" como con la historia paraguaya, atendiendo al contexto de definición de las provincias y regiones en Argentina, de los procesos de elaboración de saberes regionales y, dentro de ellos, la conformación de los campos historiográficos provinciales. Lo abordamos desde la perspectiva de una historia de la historiografía en diálogo con la antropología, la historia política, la historia cultural y de las representaciones colectivas, al considerar a la historiografía como una forma de pensar la sociedad en la dimensión espacio-temporal.

Palabras clave: historiografía; Nordeste argentino; Paraguay; regiones.

1 Universidad Nacional del Nordeste/UNNE - República Argentina.

Correo de contacto: mariasilvialeoni@hotmail.com 
Abstract: This work proposes a reflective journey on the emergence and deployment of historiography about the Argentine northeast, from the late nineteenth century to the 1970s, in connection with "national" history and with Paraguayan history, attending to the context of definition of the provinces and regions in Argentina, the processes of elaboration of regional knowledge and the conformation of the provincial historiographic fields. We approach it from the perspective of a history of historiography in dialogue with anthropology, political history, cultural history, and collective representations, considering historiography as a way of thinking society in the space -temporal dimension.

Keywords: historiography; Argentinian Northeast; Paraguay; regions. 


\section{Introducción}

Este trabajo propone trazar un recorrido reflexivo sobre la emergencia y despliegue de la historiografía referida al nordeste argentino, desde fines del siglo XIX a la década de 1970, producida tanto en vinculación con la historia "nacional" como con la historia paraguaya, atendiendo al contexto de definición de las provincias y regiones en Argentina, de los procesos de elaboración de saberes regionales $y$, dentro de ellos, la conformación de los campos historiográficos provinciales. Lo abordamos desde la perspectiva de una historia de la historiografía $(\mathrm{HH})$ en diálogo con la antropología, la historia política, la historia cultural y de las representaciones colectivas, al considerar a la historiografía como una forma de pensar la sociedad en la dimensión espacio-temporal.

La ampliación del campo de la $\mathrm{HH}$ en las últimas décadas, ha dirigido la atención a cuestiones tales como las culturas históricas ${ }^{2}$, las distintas formas de articulación de las sociedades con su pasado, principalmente a través de la memoria. Entre otros, destacamos los enfoques centrados en las maneras en que los poderes establecidos se fundan a partir de la recreación de un pasado que postulan como compartido. Así, estas perspectivas buscan desentrañar el sentido que las elites le han dado al pasado para apuntalar sus construcciones sociales y las estrategias empleadas para imponer determinadas interpretaciones ante los conflictos de memorias.

\section{Si bien ya existe una impor- tante producción sobre el papel de la historiografía en la construcción de los imaginarios nacionales en el siglo XIX y, aunque en menor medida, en el siglo XX, sólo muy recien- temente se ha comenzado a trabajar sobre la fun-}

2 La noción de cultura histórica de Jorn Rusen contempla las diferentes estrategias de la investigación científico-académica, de la creación artística, de la lucha política por el poder, de la educación escolar y extraescolar, del ocio y de otros procedimientos de memoria histórica pública, como concreciones y expresiones de una única potencia mental. (Rüsen, 1994: p. 3). 
ción social cumplida por la historia en la definición de los regionalismos y provincialismos. Para Forcadell, el "provincialismo» constituye un campo de análisis de incumbencia de la historia de las culturas políticas, la historia sociocultural y la historia de las identidades y su abordaje es una manera de reflexionar sobre el papel de la memoria en la configuración de proyectos políticos $y$ de estos en la imaginación de identidades (Forcadel, 2006: pp.6-7).

Consideramos que resulta fructífero el análisis de los agentes productores de discursos regionalistas y provincialistas, así como de los procesos de elaboración de saberes científicos que, en articulación con lo político, permitieron definir y legitimar la existencia de regiones y provincias. Los intelectuales/notables/hombres de ideas/ productores culturales -según como se prefiera denominarlos- de provincia ${ }^{3}$ han jugado un papel determinante en la tarea simbólica de construcción de los regionalismos y provincialismos, que se combina, refuerza o contrapone, según las circunstancias, con otros factores que han intervenido en la producción de estos imaginarios: la toponimia y la genealogía de categorías regionales, el discurso escolar, académico y político, la literatura de viajeros, la cartografía histórica y la iconografía oficial, la prensa y los medios de comunicación (Benedetti, 2009).

Para Bourdieu, el discurso regionalista es un dis-
curso performativo, cuya finalidad es imponer como
legítima una nueva definición de las fronteras y de
hacer conocer y reconocer la región así delimitada

3 "Los "notables" de provincia en las primeras décadas del siglo XX, que aprovechaban las ambigüedades de un capital inespecífico ligado a un apellido ilustre, a las expectativas implícitas sobre una identidad social que se vinculaba naturalmente a las letras, a las leyes, al gobierno, como una actividad entre otras, o como profesión-destino, siguen teniendo correlatos en estos bordes de la producción científica en humanidades y ciencias sociales, hoy mucho más sistematizada en un campo nacional con reglas de producción y evaluación que se imponen a duras penas en estos espacios marginales" (Martínez, 2013: p.176). 
contra la definición dominante que la ignora. El acto de categorización, cuando consigue hacerse reconocer o cuando es efectuado por una autoridad reconocida, ejerce poder por sí mismo: las categorías regionales instituyen una realidad usando el poder de revelación y de construcción ejercido por la objetivación en el discurso (Bourdieu, 2006). El regionalismo puede ser descrito a través del juego semántico que se organiza alrededor de una serie de oposiciones: Capital /Poder(es)/Ciudad/Modernidad/Cosmopolitismo versus Provincia(s)/Dominados/Mundo rural/ Tradición/Nación originaria (Thiesse, 2006: p. 59)

Si bien en la Argentina los regionalismos no adquirieron el carácter de movimientos separatistas o independentistas, ni cobraron gran protagonismo como en otros países latinoamericanos, las identidades provinciales constituyeron los factores fundamentales para activar solidaridades que entrarían en conflicto sistemáticamente con la territorialidad del estado nacional (Benedetti, 2009). Así Chiaramonte introduce el concepto de "provincia-región" al estudiar la conformación en torno a la ciudad de Corrientes ocurrida en la primera mitad del siglo XIX, pero advierte que las reiteradas e infructuosas tentativas de definir el concepto de región provienen de la inadvertencia de un conjunto de supuestos inconscientes que condujeron a convertir "el vocablo en uno de esos clichés, carente de real sustancia histórica, que proviene del uso irreflexivo del vocabulario que utilizamos" (Chiaramonte, 2008: p.21).

Al atender al papel de la historiografía en la construcción de las identidades regionales/ provinciales, se han podido establecer las particulares prácticas de integración cultural a la nación -por ejemplo, del espacio chaqueño, del correntino y del misionero, con sus marcadas diferencias- y las tensiones consecuentes. Hector Jacquet, al analizar la matriz historiográfica de los historiadores provinciales misioneros, identifica la construcción de un relato identitario alterno al del país central, con sus modos específicos de integración y diferenciación respecto tanto de la nación como del 
extranjero, y distintos intentos por articular la historia provincial con la nacional y la regional, en un complejo camino de definición de un "nosotros" frente a los "otros" (Jacquet, 1996). Estas cuestiones son centrales en espacios de frontera como los que aquí analizamos, por lo que se advierte el recurso en la argumentación histórica a la apelación a los países vecinos, ya fuera para cohesionar o para desintegrar las reivindicaciones en el seno mismo de la "comunidad nacional" que empezaba a perfilarse. De esta manera, se fueron destacando las fronteras que separaban a unos y a otros, tanto de los países vecinos (Brasil y Paraguay) como de las otras provincias (Jacquet, 1998).

El actual Nordeste argentino (integrado por las provincias de Chaco, Corrientes, Formosa y Misiones) corresponde a un espacio de tardía incorporación al estado nacional -excepto el caso de la provincia de Corrientes-, pues gran parte de su superficie lo hizo en las últimas décadas del siglo XIX bajo el estatus de territorios nacionales, con todas las diferenciaciones y restricciones políticas que ello suponía para sus habitantes, hasta que, al promediar el siglo XX, Chaco, Formosa y Misiones adquirieron el rango de provincias argentinas. Se advierten así procesos diferenciados que tuvieron asiento en cada una de las provincias/regiones que hoy lo componen.

Desde una perspectiva geográfica, "distinguir el Nordeste en su dimensión regional sólo es posible apelando a -y tal vez forzando- una agregación y diferenciación espacial resultantes de su posición en el conjunto nacional y de su contraposición a la región Pampeana, rasgo que comparte con el Noroeste" (Valenzuela, 2014). Se reconocen múltiples NEA, "tantos como territorios identificables, construidos, fragmentados, al interior, desbordando fronteras hacia el Brasil y el Paraguay", entre los cuales no se encuentran "más instancias de coordinación regional que las referidas eventualmente a la necesidad de hacer frente a decisiones tomadas desde afuera, desde Buenos Aires, capital nacional a la que le cedieron parte de sus soberanías, tal vez hace demasiado tiempo, pero haciéndolo cada uno desde su propia visión provincial" (Schweitzer, 2004). 
Las concepciones diferenciadas en torno a la región Nordeste condujeron a delinearla -cuando no a cuestionarla- de diferente manera y a buscar sus raíces históricas en diversos momentos y circunstancias. De allí que se definieran configuraciones comprendidas en este espacio bajo denominaciones tales como región misionera, región chaqueña, Litoral argentino, Mesopotamia. El río Paraná ha jugado un papel fundamental en este contradictorio proceso de vinculación/separación entre los subespacios que conforman el NEA. El dilema quedó planteado, como se indica en el Prefacio de Fulgor del desierto verde (1985), del historiador chaqueño Guido Miranda, donde se pregunta "¿Gran Chaco o Nordeste argentino?"

Intelectuales a uno y otro lado del río Paraná conformaron dos campos diferenciados -uno, en Resistencia, de formación más reciente, heterogéneo como la sociedad en la que se insertaba y que recibió la influencia tanto de los intelectuales santiagueños como correntinos, elementos que marcaron sus contradicciones; otro, en Corrientes, constituido ya en la segunda mitad del siglo XIX por integrantes de una elite política y social homogénea. Ambos disputarán desde mediados del siglo XX por la configuración de una región con nodo en sus respectivas capitales, para lo cual apelaron en sus discursos regionalistas a distintos fundamentos históricos y culturales, en los cuales Paraguay estuvo presente.

Para la construcción de saberes históricos sobre la región, podemos ensayar una periodización en dos momentos: desde fines del siglo XIX a mediados del XX, en el cual se elabora una historiografía, fundamentalmente correntina, en tensión con el Paraguay y que fortalece la idea de una región con centro en Corrientes. Una segunda etapa, a partir de los procesos de regionalización del NEA y de profesionalización de la historiografía en ese espacio, donde cambia la mirada hacia una de integración regional. 


\section{Las primeras crónicas regionales y provinciales: ¿qué región?}

En consonancia con los principios de la identidad nacional forjada por los liberales desde mediados del siglo XIX, surgió en la Argentina, así como en otros países latinoamericanos, un "centralismo historiográfico" que negó la heterogeneidad y ocultó las diferencias espaciales existentes en el nivel regional a fin de crear las historias nacionales, como síntesis y legitimación de las nacientes identidades nacionales latinoamericanas (Viales Hurtado, 2010). El marco nacional fue tomado como límite natural, con la adopción de enfoques predominantemente político-institucionales.

Paralelamente, en esos años también se elaboraron estudios históricos regionales, en los cuales la región (o la provincia) constituyó un recorte espacial considerado preexistente a la investigación. Se la concibió como "región histórica", un constructo cultural resultante de un proceso histórico que mantendría su identidad y homogeneidad desde la colonia hasta el presente (Mata de López, 2003). Así, esta historia regional/provincial se asentó sobre los mismos supuestos que establecían la legitimidad de la historia nacional, por lo que se impusieron recortes territoriales que instituyeron a un espacio como estado nación y al otro como región histórica (Carbonari, 2009).

El análisis de Peiró Martin para el caso español permite establecer un paralelo con el caso argentino: estos discursos «liberal provincialistas» se elaboraron "desde la reivindicación cultural de que estos elementos diferenciales y detalles significativos fueran reconocidos en el contexto general del pasado nacional", con el convencimiento de que "los pasados de sus localidades eran partes complementarias y nunca representaciones alternativas y separadas, distintas o antagónicas, de la cultura histórica nacional" (Peiró Martin, 2006: p.264).

Desde la segunda mitad del siglo XIX, los gobernantes correntinos se preocuparon por fortalecer una memoria colectiva que exaltaba el heroísmo de Corrientes en las luchas por la construcción de una Argentina 
democrática y federal. La labor historiográfica de los intelectuales locales cumplió un papel central en la definición provincial. En las últimas décadas del siglo XIX, se partía de un diagnóstico desfavorable sobre el lugar asignado a la provincia al producirse la integración al estado nacional. Los primeros relatos históricos comenzaron a escribirse desde el lugar de una elite escindida, que percibía su alejamiento de los primeros planos de la política nacional y el derrumbe de sus expectativas en el terreno económico.

El historiador correntino Hernán Gómez ${ }^{4}$, en la década de 1920 consideraba que, frente al centralismo porteño y el avance de ideas políticas extremas, debía edificarse en el norte del Litoral argentino "una provincia fuerte, de representación electoral máxima, que pese en los destinos de la República y custodie en la Mesopotamia la estirpe argentina y su idealidad maravillosa" (Gómez, 1928: 18). Gómez proponía entonces constituir a Corrientes en centro de la Mesopotamia. Sus obras his- tóricas servirán para fundamentar esta anhelada integración.

Las otras actuales provincias del nordeste argentino (Formosa, Chaco y Misiones) tuvieron un desarrollo historiográfico tardío e inicialmente subsidiario del correntino, marcado por las características de su particular organización institucional y posterior provincialización, ya en la década de 1950. En estos espacios organizados como territorios nacionales, las representaciones elaboradas en la segunda mitad del siglo XIX provinieron de los discursos de los representantes del gobierno nacional y de quienes pertenecían a instituciones vinculadas con el mismo -como el Instituto Geográfico Argentino y la Sociedad Geográfica Argentina-, integradas por funcionarios, militares y aficionados involucrados en las prácticas de apropiación material. Sus trabajos sostenían la imagen del desierto, que representaba vastos espacios sin historia, dotados de existencia a partir de los descubrimientos de las empresas exploradoras y

4 H. F. Gómez (1888-1945) Político autonomista, educador y periodista, llegó a convertirse en el "historiador oficial" de Corrientes en las décadas de 1920 y 1930. 
colonizadoras (Lois, 1999). Muy lentamente se iría desarrollando en ellos una incipiente historiografía local, que ubicaba el punto de partida de la historia en los procesos de ocupación de los espacios por parte del estado nacional (Leoni, 2014).

En el caso de la historiografía correntina, una de las cuestiones omnipresentes es el supuesto de que un enorme espacio, "la provincia guaraní", organizado en torno al predominio de la ciudad capital, estaba llamado a ocupar un lugar hegemónico en la historia nacional, pero que debido a los avances extranjeros (paraguayos y portugueses primero y brasileños después) y a la despreocupación de los gobiernos españoles y porteños, fueron reduciendo y marginando. El corolario de este proceso de desmembración de la gran provincia correntina habría sido la separación de Misiones, convertida en territorio nacional en 1881 , bajo directa administración de las autoridades centrales.

Como fundamento de las pretensiones correntinas, constantemente se ha esgrimido el acta de fundación de la ciudad de Corrientes, suscripta por el adelantado Juan Torres de Vera y Aragón el 3 de abril de 1588, que constituye la pieza principal que asigna a la ciudad de Vera sus límites y términos ${ }^{5}$. Estos fueron entendidos por todos los historiadores correntinos como la jurisdicción que correspondía definitivamente a la ciudad. Manuel F. Mantilla (1853 - 1909) lamentaba que, con el tiempo, estos límites originales fueran sucesivamente restringidos por desmembraciones territoriales abusivas, hasta quedar reducidos a los de la contemporánea provincia de Corrientes.

Hernán Gómez creía que Corrientes "situada a las puertas del Alto Paraná, que se introduce como una cuña en el seno de

\footnotetext{
5 El acta sostenía "Fundo y asiento y pueblo la ciudad de Vera en el sitio que llaman de las siete Corrientes, provincia del Paraná y el Tape, con los límites e términos siguientes: de las ciudades de Asunción, Concepción de la Buena Esperanza, Santa Fe y San Salvador, Ciudad Real, Villa Rica del Espíritu Santo, San Francisco y Biazá, en la costa del mar del norte, para agora y siempre jamás, en el entretanto que Su Majestad o por mi otra cosa no sea mandado en su real nombre..." (Cit. Por Maeder, 2006).
} 
la referida provincia de Vera, estaba llamada a sustituir a la Asunción, y así el Adelantado fundador asígnale la más amplia de las jurisdicciones". La conquista y colonización hispana revelan, para Gómez, un desarrollo armónico. Encuentra en las diversas corrientes colonizadoras la piedra inicial del federalismo y, en el ordenamiento adoptado por la corriente de la Mesopotamia, la razón de existir de cuatro provincias (Buenos Aires, Santa Fe, Entre Ríos y Corrientes) y de la República del Paraguay. Corrientes nació como broche de oro de la gestión del Adelantado Juan Torres de Vera y Aragón para ser el corazón de la conquista en la zona oriental, hasta el Atlántico.

Pero, “¿por qué Corrientes no heredó a Asunción en la hegemonía política y, en cambio, fue perdiendo su importancia y reduciendo su jurisdicción?" Encuentra causas inmediatas, como la renuncia del Adelantado Juan Torres de Vera y Aragón, que restó el cerebro de quien concibiera este plan de gobierno, y la sustitución de Alonso de Vera y Aragón, cuyos sucesores no estuvieron a la altura de sus deberes. Más allá de esto, la causa fundamental fue que España cambió el orden económico-administrativo de la zona oriental, con el establecimiento de las misiones jesuíticas. Fueron ellas las que impidieron que Corrientes cumpliera con el papel que le había sido asignado.

Los historiadores correntinos construyeron una visión de la provincia como una avanzada de la nacionalidad, hacia adentro de los límites del país, por su defensa de la tradición y de los principios que se consideran rectores de la historia argentina: federalismo, democracia; hacia afuera, como valla de las penetraciones del extranjero, ante la desidia de los gobiernos centrales. Su papel en los procesos independentistas de la región y en la construcción del estado nacional es considerado clave por ellos.

Gómez distingue en el período independiente distintos acontecimientos básicos de la contribución de Corrientes a la defensa territorial de la nación, el primero de los cuales fue la campaña al Paraguay, realizada por Manuel Belgrano: Corrientes había contribuido en la lucha contra el centro españolista de 
Asunción y fue quien sembró las semillas de la independencia paraguaya (Gómez, 1928: p.49).

Por otro lado, uno de los elementos considerados identitarios sería la raíz hispano-guaraní o sólo guaraní, según el caso. Gómez reconoce "el sello de la raza guaraní, señorial y autóctona, que está en la toponimia, en el lenguaje popular, en el tipo racial de la masa que construye" (Gómez, 1944: 151). Esta perspectiva se manifiesta claramente en Wenceslao N. Domínguez (1898-1984), quien rescata este último elemento, al que considera que la historiografía anterior no había ponderado suficientemente. Al hacer hincapié en que Corrientes había estado marcada desde su origen por la idea de autonomía, determinó que fue la conjunción hispano-guaraní la que fundamentó y desarrolló el carácter democrático y federal de las incipientes instituciones" (Domínguez, 1973: p.14).

Propuso la recuperación del idioma a través de la Academia Correntina del Idioma Guaraní, que creara en Buenos Aires en 1940. En su obra El idioma guaraní. Filosofía-ra- za-lengua (1971), señala la necesidad de adentrarse en la historia para conocer la evolución social y política de las generaciones autóctonas, para rescatar la participación del indígena en la nacionalidad: "En la zona guaranítica esta raza también ofrece al estudioso la evidencia de un factor positivo e intensamente influyente en la formación de la sociedad que el conquistador europeo impuso con fuerza inmoderada" (Domínguez, 1971: p.7). Critica que la historia y la lengua se estudiaron desde afuera, con criterio europeo y propone analizarlas desde adentro, desde la singularidad de esta cultura. Tras demostrar cómo hubo una política oficial, destinada a terminar con el mundo guaraní a través de la supresión de su lengua, propone revertirla, ya que la recuperación del idioma significa también la de todo un legado espiritual que debe enorgullecer a sus beneficiarios.

La Guerra de la Triple Alianza (1865-1870) fue un acontecimiento clave en el proceso de consolidación del Estado nacional argentino, al mismo tiempo que un tema de conflictivo tratamiento para la 
historiografía correntina, la que mantuvo en general un cauteloso silencio sobre el mismo, o bien lo trató superficialmente, para evitar, fundamentalmente, la revisión del papel jugado por las familias patricias correntinas en esos acontecimientos. Considerándose heredera de Bartolomé Mitre, la historiografía correntina se alineó en su perspectiva. Al respecto escribió Mitre al trazar una interpretación del pasado correntino:

Corrientes, limítrofe con el Paraguay, con el Brasil y con el Estado Oriental, es nuestro antemural por la extremidad norte, y es una fuerza que da cohesión a la población de esa parte del territorio argentino, que parece desprenderse de nuestro sistema geográfico.

Piénsese por un momento lo que habría sido la guerra del Paraguay en 1865 y 1866 sin ese temple guaraní, cuando al ponerse en campaña los primeros batallones argentinos, se sublevaron sucesivamente dos ejércitos entrerrianos a su retaguardia, a que debían responder más tarde otros dos ejércitos en el interior de la República, que se levantaron en honor de López del Paraguay, y icuando en nuestra prensa y en nuestro parlamento no faltaba quien abogase por la causa del Paraguay!

\section{La provincia de Corrientes fue nuestra vanguardia en la guerra contra los guaraníes bárbaros que nos trajo el Paraguay, y ella ha contribuido a ase- gurar por un siglo más nuestra paz exterior por aquella parte de nuestras fronteras, vinculando per- durablemente la Mesopo- tamia argentina a nuestro sistema político, geográ- fico y social (Mitre, 1878).}

Mantilla señalará que la provincia comenzaba a reponerse de las luchas contra Rosas, cuando "cayó sobre ella, de sorpresa, en plena paz y con violación de la fe de las naciones, la invasión de dos poderosos ejércitos paraguayos acto continuo de haber sido traidoramente tomados a mano armada por la escuadra del mismo país" (Man- 
tilla, 1928: t.Il, p. 275). Sobre la complicidad de dirigentes correntinos con el Paraguay, se limita a señalar que "ciegos miembros del partido federal (recordemos que Mantilla era liberal) se plegaron al enemigo extranjero"; destaca el "oprobio estéril" de la Junta paraguayista establecida en Corrientes, "mero aparato de ostentación, sin voluntad propia, sin influjo, sin autoridad", mientras que la provincia debió soportar el terror, con saqueos y ultrajes, el despotismo, la miseria. Resalta el heroísmo de Corrientes en la defensa del territorio, así como en el aprovisionamiento de las tropas al avanzar sobre territorio paraguayo. Cabe señalar que esta perspectiva de Mantilla es coetánea de una visión de la historiografía paraguaya que responsabilizaba exclusivamente a Carlos Solano López por la guerra (Brezzo, 2004: pp.15-17). Pero el revisionismo argentino posterior no incidirá en la historiografía correntina para revisar este tema.

Será curiosamente el episodio de las "cautivas correntinas" que, pese a no contar con registro escrito, el único constantemente referenciado, trans- mitido oralmente y plasmado en el monumento erigido en honor a Mitre (Quiñonez, 2013).

La participación correntina en favor del Paraguay, minimizada y ocultada, será objeto de un análisis, aunque aislado, posterior. Al cumplirse el centenario de la ocupación de Corrientes por las tropas paraguayas, Domínguez publica La toma de Corrientes. El 25 de mayo de 1865 , por considerarlo "un asunto ignorado en muchos aspectos por cuanto el acontecimiento histórico fue contemplado únicamente desde afuera y los hechos que ocurrieron en el escenario de Corrientes, han quedado sin que llamaran la atención de los estudiosos" (Domínguez, 1965: p.16). Al preguntarse por los motivos de ese silencio, simplemente responde "por inconfesables razones", sin entrar en ellas. El mismo silencio se advierte en las historiografías que se desarrollarán en los territorios nacionales del NEA, luego provincias, cuyas referencias a la guerra se limitan a la problemática de la definición de los límites.

Ya en este siglo, se ha comenzado a retomar 
la cuestión, a través de la recuperación de fuentes tales como los expedientes judiciales y los periódicos de la época, que permiten tener una visión más aca- bada del tema, pero que muy incipientemente se han introducido en el análisis de las relaciones entre Corrientes y Paraguay .

\section{La creación del Nordeste}

Hacia mediados del siglo $X X$, en el Chaco comienzan a convivir la denominación Litoral Norte con la Nordeste -cuyos precisos orígenes no hemos podido determinar, pero que consideramos aparece como correlato del proceso de regionalización del Noroeste argentino. En 1945, el Ateneo del Chaco, institución pública no oficial señera en el campo intelectual del territorio, organizó el Primer Congreso de Instituciones Culturales del Litoral Norte y del Paraguay.
En 1954, Guido Miranda7 en El paisaje chaqueño, presentado como un ensayo de geografía regional, sostiene que "existe una notoria compenetración regional de nuestra provincia con el Gran Chaco, del cual está llamada a ser la cabecera económica", lo que confirma el "destino regional del Chaco" (Miranda, 1954: p.14).

Ramón de las Mercedes Tissera ${ }^{8}$ opone a la noción Nordeste, que comienza a imponerse, la de Gran Chaco, región esta última que comprendería

$6 \quad$ Una de estas excepciones son los trabajos de Dardo Ramírez Braschi (2019). Corrientes y Paraguay. Una relación de conflictos y armonías (1810-1860). Corrientes, Moglia.

7 Guido Miranda (Vera, Santa fe,1912- Resistencia,1994). Maestro, integró la redacción de distintos periódicos y dirigió la revista Región. Se incorporó a las filas del socialismo a fines de la década de 1940 y participó en la Convención Constituyente de 1957. Su labor historiográfica comenzó en las postrimerías del gobierno peronista. Su obra Tres ciclos chaqueños (1955) se convertiría en un clásico de la historiografía chaqueña.

8 Ramón de las Mercedes Tissera (Córdoba, 1920- Resistencia,1981). Se radicó en Chaco desde edad temprana. Periodista y político. Militante de la UCR primero y luego de la UCRI, fue diputado provincial entre 1958 y 1966. 
las provincias de Chaco, norte de Santa Fe, este de Salta y Formosa. A través del análisis histórico, se propone recomponer una trayectoria de siglos, desde las primeras poblaciones indígenas, y demostrar la historicidad de la región propuesta.

A nivel nacional, las políticas territoriales que buscaban solucionar los problemas de escaso crecimiento y desequilibrios sociales internos, apelaron a las teorías regionales que dejaron en el mapa argentino algunas marcas. Estas regionalizaciones respondían a la necesidad de contar con instrumentos dotados de cierto consenso científico, para clasificar las riquezas y potencialidades de las distintas localizaciones del territorio nacional, con vistas a profundizar el proceso de inserción de la economía local en el espacio mundial, así como estrategias de integración y jerarquización de los sectores sociales comprendidos o simbolizados (Benedetti, 2009)

En el año 1967, por medio de un decreto del gobierno de facto de Juan Carlos Onganía, se estableció la división de la Argentina en ocho regiones.
La definición de la región Nordeste (NEA) formó parte de ese proceso de regionalización. Según el decreto, la región abarcaba un amplio territorio que incluía a las provincias de Chaco, Corrientes, Misiones y Formosa y los departamentos de Vera, General Obligado y Nueve de Julio ubicados al norte de la provincia de Santa Fe.

Al analizar el campo intelectual conformado en la segunda mitad del siglo XX en torno a la Universidad Nacional del Nordeste, creada en 1957 , advertimos el dilema que debió enfrentar al fundamentar los estudios regionales nordestinos frente a la comprobación, a través de estos mismos estudios históricos y geográficos, de su existencia meramente programática (Leoni, 2015). Jacquet señala que, para dotarla de existencia, la región nordeste precisaba de una historia que la fundara y fundiera en rasgos específicos. Así surgiría una historiografía de construcción nordestina que "debió hilvanar los retazos de las historias de cada provincia para sustentar la existencia de una región Nordeste que resultaba ser bastante inédita y reciente" (Jacquet, 2002: p.52). Estas serían 
las bases de lo que denomina historiografía nordestina, que permitía conferir un pasado común a la nueva región, más allá de las irresolubles dificultades teóricas y metodológicas que planteara su abordaje.

Así, Miranda, no obstante sus trabajos centrados en la región chaqueña, realizaría el esfuerzo por fundamentar históricamente la regionalización del Nordeste en una serie de artículos titulados "Perfil del Nordeste" publicados en el diario El Territorio de Resistencia en 1968 y 1969. Miranda señala en dichos artículos que esta unidad regional es un enfoque contemporáneo a la creación de la UNNE y aunque señala que el Nordeste no presenta una unidad geográfica, considera que sí la tiene en cuanto a la ocupación humana, homogeneizada por la cultura guaraní. Sin embargo, la determinación regional para Miranda, no significaba la recuperación del legado indígena, sino el aporte manifiesto que éste había dejado en el folklore, las leyendas y la música.

El Consejo Nacional de Ciencia y Tecnología (CONACYT) creó en 1969 el Programa de
Estudios Regionales (PER) y la Comisión Regional NEA de Ciencia y Técnica, en consonancia con una política que privilegiaba el desarrollo científico y tecnológico en el interior del país a través de una división en regiones. El Programa de Estudios Regionales se proponía "dar inicio a los estudios regionales en la Argentina desde una perspectiva interdisciplinaria", auspiciado por organismos nacionales de Argentina y Paraguay, ligados al Programa "Impacto de las Grandes Obras Hidroeléctricas del Río Paraná sobre el sur del Paraguay y Nordeste de la Argentina" coauspiciado por el Consejo Nacional de Investigaciones Científicas y Técnicas de la Argentina y el Consejo Nacional de Progreso Social de Paraguay (Espínola, 1976). En ese mismo marco, el PER, firmó un convenio con la UNNE para que investigadores de la Universidad participaran del programa.

El Programa editó la Revista de Estudios Regionales (1976-1978). En su presentación, afirmaba que se proponía "dar inicio a los estudios regionales en la Argentina desde una perspectiva interdisciplinaria [...] y ofrecer un panorama lo más 
completo posible del Nordeste" (Espíndola, 1976). A través de la publicación de la revista y posteriormente de la Colección Estudios Regionales (1978-1982), investigadores de las diversas disciplinas sociales y humanas pudieron difundir los resultados de sus investigaciones y reflexionar sobre la posibilidad de existencia de una región NEA.

Según sus propias palabras, cuando se radicó en Resistencia, Ernesto Maeder ${ }^{9}$, quien iniciaría los estudios históricos profesionales en la Universidad Nacional del Nordeste, no se encontró con una historia regional, sino con historias provinciales, lo que se justificaba en la asincronía en la constitución histórica de los distintos espacios que componen la región. Encararía entonces los esfuerzos por llevarla a cabo. Lo haría siguiendo el modelo de historia regional de Anales que entonces se desarrollaba en Francia, que combinaba "las estructuras de Braudel, la coyuntura de Labrousse y la nueva demografía histórica" (Burke, 1993: p.62). El nombre dado al Instituto que creara en 1979 "Instituto de Investigaciones Geohistóricas" evidencia esta perspectiva adoptada.

En la Revista de Estudios Regionales, Maeder publicó una "Breve historia del Nordeste Argentino en su relación con Paraguay y Río Grande do Sul" (1977), que constituye una de las primeras formulaciones de una región histórica del Nordeste que, además de las provincias argentinas, debía incluir necesariamente Paraguay y sur de Brasil, espacio geográfico amplio que fuera escenario de las misiones de guaraníes. Como se observa, la delimitación de la región responde a una concepción de región histórica que hunde sus raíces en la época colonial y en el recorte del mundo jesuítico. En este sentido se orientaría gran parte de la producción de Maeder, desde la edición crítica de fuentes, como las Cartas Anuas de la Provincia

9 Ernesto Maeder (Buenos Aires,1931-Resistencia,2015). Profesor de Historia, en 1958 se radicó en Resistencia, para desempeñarse en la Universidad recientemente creada. Fue decano de la Facultad de Humanidades y rector de la Universidad Nacional del Nordeste. Creó y dirigió el Instituto de Investigaciones Geohistóricas (CONICET). 
Jesuítica del Paraguay, hasta sus principales obras históricas. La culminación de este esfuerzo sería el Atlas Histórico del Nordeste Argentino (1995) y el Atlas histórico y del desarrollo urbano del nordeste argentino. Paraguay, Corrientes y Misiones, que dirigiera junto con el arquitecto Ramón Gutiérrez.

No obstante, haciendo un balance al final de su recorrido, Maeder reconocería que no llegó

\section{Consideraciones finales}

Los esfuerzos por rastrear la historia de la región Nordeste en momentos anteriores a su definición programática que tiene lugar a mediados del siglo $X X$, y plantearla como región histórica, han resultado uno de los principales obstáculos para el desarrollo de la historia regional en estos espacios. Los estudios historiográficos, más allá de sus diversas perspectivas, terminaron por reforzar la idea de la existencia en el espacio nordestino de dos o tres regiones con desarrollos diferenciados.

La historiografía correntina buscó resaltar la contribución de la provincia a la historia nacional, por considerar que a realizar una historia del NEA y consideró que el Atlas constituyó la base, el planteo del problema que aun debía ser resuelto, ya que, como señalara antes, "lo que al observador se le impone son procesos sincrónicos, pero independientes; en ocasiones interrumpidos, [...] y que sólo alcanzaron una cierta unidad en la medida que los contactos fronterizos lo hicieron posible" (Maeder, 1976: 41).

no había sido justipreciada, sino que el país con centro en Buenos Aires la olvidó y marginó, sentimiento que ha alimentado sus esfuerzos por proyectarse sobre la región y acercarse a sus vecinos, en una mirada en la que coexisten el descubrimiento de elementos y problemas comunes, como la raíz guaraní, que permiten una proximidad mayor con el "otro" extranjero, al mismo tiempo que trazan las distancias con Buenos Aires. No obstante, atendiendo siempre resaltar su inclusión en un marco nacional. A pesar de las estrechas -y complejas- vinculaciones del pasado correntino con el del Paraguay y quizá por eso, no existió intercam- 
bio entre sus historiadores. La nos, más allá de los múltiples mirada del mitrismo se man- vínculos, como "otros" que constendría a través del tiempo. tituyeron peligros constantes para el territorio argentino.

Por su parte, la historiografía del espacio chaqueño y del misionero rescató el papel del estado nacional para su incorporación a la nación y al mundo "civilizado"; buscó separarse de la pretensión hegemónica correntina y legitimar su autonomía. En todos los casos, por tratarse de espacios de frontera, cuya ocupación y fijación de limites fueron procesos determinantes para la configuración del estado nacional, no pudieron dejar de ver a los países veci-

El desarrollo de una historiografía profesional a partir de la década de 1960 enmarcada en los procesos de regionalización estatal, se propuso integrar el espacio regional nordestino, más allá de los límites políticos, atendiendo a la identificación de las dinámicas poblacionales y económicas que lo atravesaron. La perspectiva geohistórica, aplicada fundamentalmente para el período colonial, constituiría un aporte significativo. 


\section{Referencias bibliográficas}

Benedetti, A. 2009. “Los usos de la categoría región en el pensamiento geográfico argentino", Scripta Nova. Revista Electrónica de Geografía y Ciencias sociales, 286, s/p. Disponible en http://www.ub.es/geocrit/sn/sn286.htm

Bourdieu, P. 2006. “La identidad y la representación: elementos para una reflexión crítica sobre la idea de región", Ecuador Debate, 67. Disponible en http://www.dlh.lahora.com.ec/paginas/debate/paginas/debate1637. htm.

Brezzo, L. 2004. “La guerra de la Triple Alianza en los límites de la ortodoxia: mitos y tabúes", Universum, Universidad de Talca, 19: pp.10-27.

Burke, P. 1993. La revolución historiográfica francesa. Barcelona, Gedisa.

Carbonari, M.R. 2009. “De cómo explicar la región sin perderse en el intento. Repasando y repensando la Historia Regional", História Unisinos, 13 (1): pp. 19-34.

Chiaramonte, J.C. 2008. "Sobre el uso historiográfico del concepto de región", Estudios Sociales, Revista Universitaria Semestral, 18 (35): pp. 7-21

Domínguez, W. 1973. Corrientes en las luchas por la democracia. El artiguismo en Corrientes. Buenos Aires, Imp. La Gráfica.

Domínguez, W. 1971. El idioma guaraní. Filosofía-raza-lengua. Buenos Aires, Imp. La Gráfica.

Domínguez, W. 1965. La toma de Corrientes. El 25 de mayo de 1865. Homenaje a su centenario 1865-1965. Bs.As., Imp. López.

Espínola, J. 1976. "Presentación”, Revista de Estudios Regionales, año I, No1, Corrientes, PER-CONICET.

Forcadell, C.M. y Cruz Romeo, M. (Ed). 2006. Provincia y nación. Los territorios del liberalismo. Zaragoza, Institución «Fernando el Católico» (C.S.I.C.) Excma. Diputación de Zaragoza.

Gómez, H.F. 1928. Historia de la provincia de Corrientes. Corrientes, Imp del Estado. T.I.

Gómez, H.F. 1944. Nuestra Señora de Itatí. Buenos Aires, Ed. Corrientes.

Gómez, H.F. 1928. Páginas de historia. Corrientes, Imp del Estado.

Jacquet, H. 1996. Haciendo Historia en la aldea. Posadas: Edición del autor.

Jacquet, H. 1998. Los historiadores y la producción de fronteras. El caso de la provincia de Misiones (Argentina). En: UNESCO, MOST, Documentos de debate $\mathrm{N}^{\circ} 29,1998$ www.unesco.org/most 
Leoni, M.S. 2015. “Elites culturales y construcción de la región en el nordeste argentino en el siglo XX", Coordenadas, 2.

Leoni, M.S. 2014. "Política e historia en el Chaco de la década de 1930", Cuadernos del Workshop, : 45 - 56.

Lois, C. 1999. “La invención del desierto chaqueño. Una aproximación a las formas de apropiación simbólica de los territorios del Chaco en los tiempos de formación y consolidación del estado nación argentino", Scripta Nova. Revista Electrónica de Geografía y Ciencias sociales, 38. Disponible en http://www.ub.edu/geocrit/sn-38.htm

Maeder, E. 1977. “Breve historia del Nordeste Argentino en su relación con el Paraguay y Río Grande do Sul". En: Revista de Estudios Regionales, año $1, N^{\circ} 2$, Corrientes (separata).

Maeder. E. 2004 "La historiografía correntina. Algunas observaciones sobre su visión de la época colonial en esa provincia". En: Ernesto Maeder, María Silvia Leoni, María Gabriela Quiñonez y María del Mar Solís Carnicer. Visiones del pasado. Estudios de historiografía de Corrientes. Corrientes, Moglia.

Mantilla, M. 1928. Crónica histórica de la Provincia de Corrientes. Corrientes, Imp. Del Estado.

Martínez, A.T. 2013. Intelectuales de provincia: entre lo local y lo periférico Prismas, Revista de historia intelectual, Nº17, 2013, pp. 169-180

Mata de López, S. 2003. “Historia local, historia regional e historia nacional. ¿Una historia posible?", Revista Escuela de Historia, 1 (2), s/p. Disponible en www.unsa.edu.ar/histocat/revista/revista0203.htm

Mitre, B. 1878. Ayerecó Qaha Catú. Una provincia guarani. Buenos Aires, Coni. s/p.

Peiró Martin, Ignacio. 2006. “Los historiadores de provincias: la historia regional en el discurso histórico de la nación". En: Forcadell Álvarez, Carlos María y Cruz Romeo Mateo (Ed). Provincia y nación. Los territorios del liberalismo. Zaragoza, Institución «Fernando el Católico» (C.S.I.C.) Excma. Diputación de Zaragoza.

Quiñonez, M.G. 2013. “Historias que nunca se escribieron. Las cautivas, la guerra del Paraguay y la Historiografía correntina". En: Juan Manuel Casal y Thomas Whigham, ed. Paraguay: Investigaciones de historia social y política. Asunción, Ed. Tiempo de Historia. pp. 311-326.

Ramírez Braschi, D. 2019. Corrientes y Paraguay. Una relación de conflictos y armonías (1810-1860). Corrientes, Moglia.

Rüsen, J. 1994. “¿Qué es la cultura histórica?: Reflexiones sobre una nueva manera de abordar la historia", en Culturahistórica. [Versión castellana 
inédita del texto original alemán en K. Füssmann, H.T. Grütter y J. Rüsen, eds. Historische Faszination. Geschichtskultur heute. Keulen, Weimar y Wenen: Böhlau, pp. 3-26.

Schweitzer, A. 2004. "¿Uno o varios NEA? Regiones y Territorios en el espacio del Nordeste Argentino". En: Marta Panaia y otros. Crisis fiscal, mercado de trabajo y nuevas territorialidades en el Nordeste Argentino. Buenos Aires, La Colmena.

Thiesse, A.M. 2006. "Centralismo estatal y nacionalismo regionalizado. Las paradojas del caso francés", Ayer 64 (4): pp. 33-64

Valenzuela, C. 2014. "Principales problemáticas y potencialidades de la región Nordeste". Geograficando, vol. 10, N². Disponible en: http://www. geograficando.fahce.unlp.edu.ar/article/view/Geov10n02a07.

Venegas Delgado, H.M. 2012. "La región en su perspectiva histórica”, Estudios del Ishir, 2 (4): pp. 3-26.

Viales Hurtado, R. 2010. “La región como construcción social, espacial, política, histórica y subjetiva. Hacia un modelo conceptual/relacional de historia regional en América Latina", Geopolítica(s). Revista de estudios sobre espacio y poder, 1: pp. 157-172. 
